\title{
Interactions between spray drift and sprayer travel speed in two different apple orchard training systems
}

\author{
M. Lešnik $\cdot$ D. Stajnko $\cdot$ S. Vajs
}

Received: 22 May 2013/Revised: 14 May 2014/Accepted: 22 November 2014/Published online: 11 December 2014

(C) Islamic Azad University (IAU) 2014

\begin{abstract}
Trials were carried out in apple orchards of two different training systems to assess the relationship between spray drift and parameters of spraying with an emphasis on the sprayer's travel speed when applying different solutions, such as pesticides or fertilizers, onto the apple trees. The assessments were based on the following factors: per cent of spay drift, two sprayers (axial- and radial-fan sprayer), two training systems (super spindle and modified slender spindle), spray droplet size (fine or coarse droplets) and the sprayer's travel speed (5 vs. $10 \mathrm{~km} \mathrm{~h}^{-1}$ ). The studies were conducted in the spring and summer seasons under similar external weather conditions to test any seasonal effects that might occur. In this paper, all tested factors and interactions were found to have a significant effect on the spray drift during spray application. For instance, the increase in sprayer speed reduced the spray drift percentage. Other factors, such as sprayer type (axial fan and radial fan) and tree training system, had an impact on spray drift as well.
\end{abstract}

Keywords Adjacent areas - Application of pesticides . Pollution

Electronic supplementary material The online version of this article (doi:10.1007/s13762-014-0724-7) contains supplementary material, which is available to authorized users.

M. Lešnik ( $₫) \cdot$ D. Stajnko · S. Vajs

Faculty of Agriculture and Life Sciences, University of Maribor, Pivola 10, 2311 Hoče, Slovenia

e-mail: mario.lesnik@uni-mb.si

\section{Introduction}

The intensive use of different varieties of agrochemicals is one of the attributes of modern orcharding. Fruit tree plantations are special types of facilities for industrial agricultural production, which may pose an environmental threat in form of aerial drift, surface run-off and leaching of pesticides, fertilizers and other applied agrochemicals. Apple orchards are treated with pesticides 15-25 times per season. The high frequency of pesticide application represents one of the most serious pollution threats to the neighbouring environment among all the various agricultural production systems. Large plantations are often situated close to urban areas and close to sensitive nature areas; therefore, constant improvement in pesticide application techniques is needed to prevent pollution related to drift during the application of pesticides in orchards. Nowadays, tractor-driven air blast sprayers are the most frequently used devices for pesticide application in orchards. These produce an air jet for projecting spray into the tree canopy. The plume of pesticide spray produced by a sprayer often does not completely match the tree canopy geometry. It frequently partially misses the tree canopy and is accelerated upwards into the air above the canopy or passes through the target canopy (Cross 1991). This causes an exo-drift, which is defined as the physical movement of pesticide droplets or particles through the air from the target site (the orchard) towards any non-target sites like adjacent vegetation, other crops, water bodies and residential areas (Matthews 2000). In modern apple plantations, $25-35 \mathrm{~kg}$ of active pesticide ingredients is usually applied per hectare per season (Garthwaite et al. 2010; Urek 2012). Approximately 1-4\% of the applied hectare rates of pesticide drift beyond the orchards to the neighbouring areas (Ganzelmeier et al. 1995). The drift 
regulations oblige farmers to carry out all possible drift mitigation and reduction measures (adaptation of the sprayer's operational settings, use of drift-reducing nozzles, application of spray with shields and other).

Pesticide drift-reducing technology most often refers to designing application equipment or chemical product formulation but does not always integrate the specific ways of equipment usage. The sprayer forward speed represents one of the basic sprayer operation settings that influence sprayer performance. Changes in the sprayer forward speed influence its spray deposition pattern and drift characteristics. For economic reasons, the acreages of orchard farms are increasing constantly, and growers are seeking all possible means of time and cost savings. Pesticide application operations often have a very limited time frame because of weather conditions, dependence on specific development stages of diseases and pests, the limited period of curative activity of fungicides and other reasons. One way to gain time and cost savings on pesticide application is to increase the sprayers' travel speed. Information about optimum sprayer speed is important for growers because of spraying economics as well as its potential effect on drift reduction (Triloff 2005).

An increase in sprayer travel speed influences the geometry of the sprayer air plume and its movement through the tree canopies and the orchard environment (Whitney and Salyani 1991). When calibrating sprayer settings, the advice that the air velocity and sprayer air flow rate need to be increased when moving faster is usually followed. As forward speed rises, the spray air plume can be diverted backwards into upwards wind currents and vortices behind the sprayer. This can be advantageous, especially in the spring when there is little foliage on the trees. When the air stream bends backwards, it lingers longer in the canopy; it thus improves deposition and also decreases drift (Derksen et al. 2006). On the other hand, this can increase the variability of deposits within the tree canopy and ground deposition beneath and between tree rows (Świechowski et al. 2004; Sehsah 2007). Ground deposition inside the orchard is identified as internal drift (endo-drift). In the literature, there are few data available describing the interactive effects among sprayer speed, sprayer operating setting, tree canopy structure and spray drift to adjacent areas for modern plantations with dwarf apple trees (Jejčič et al. 2011; Triloff 2011).

In many field experiments with field boom sprayers, it was found that increasing the sprayer speed increases the drift (Arvidsson 1997; van De Zande et al. 2005; Nuyttens et al. 2006). Similar findings were published for air blast sprayers during pesticide application in vineyards (Celen et al. 2008). In orchards, different interactions are expected between travel speed and drift than in the field crops. According to most literature claims, drift in orchards decreases with an increase in sprayer travel speed (Fox et al. 1990; Walklate et al. 1996; Sehsah 2007; Triloff 2005, 2011). It seems that there is a very complex relation between sprayer forward speed, tree canopy structure and sprayer drift characteristics. That relation has not yet been studied in detail in the past. The main factors that govern spray drift during the spray application of pesticides in orchards are as follows: weather conditions, sprayer operating parameters, droplet size, type of sprayer, the characteristics of its air plume and the characteristics of tree canopies (Ganzelmeier et al. 1995; Derksen et al. 2006, 2007).

A certain level of spray drift during pesticide application in orchards is inevitable. Because pesticide drift is of legal and public concern, all possible drift-reducing measures need to be employed during any application.

The aims of this research were as follows: (1) to improve understanding of interaction between sprayer travel speed and the amount of spray drift in modern apple orchards planted with dwarf trees and (2) to check whether an increase in sprayer travel speed reduces drift so significantly that the increased speed could be considered an important measure for pesticide spray drift reduction during pesticide application in apple orchards.

Drift assessments were conducted in the orchards owned by the Experimental station of the University of Maribor (Hoče near Maribor, Slovenia) during the 2012 season.

\section{Materials and methods}

\section{Treatment area description}

The orchard where the trials were carried out was established on a flat field and consisted of two blocks, each measuring 0.7 ha. In the first section, 'Fuji' apple trees were trained as super spindle trees (SSP), and in the second section in a form of modified slender spindle tree (MSP). The tree characteristics are shown in Table 1. The rows of trees in block 1 were $2.8 \mathrm{~m}$ apart and in the second block, $3.8 \mathrm{~m}$ apart. For determining the leaf area index (LAI), half the leaves were first clipped from several trees involved in the experiment. Then, the area was calculated by scanning each leaf separately on a Samsung scanner and applying our own software, entitled 'Leaf area calculator'. Finally, the double total area of the leaves collected per tree was divided by the ground area belonging to the individual tree.

On the left side of the orchards, there were fields, and on the right side, the meadow where the drift collectors were placed. The test site was set up, and drift was measured according to the ISO/FDIS 22866 standard (Anonymous 2005).

\section{Statistical design}

The field trial was designed as a factorial trial, with five factors studied at two levels in five replications, as follows: 1-type of sprayer (axial and radial fan), 2-tree training 
Table 1 Some canopy characteristics of 8-year-old trees during spring (1) and summer (2)

\begin{tabular}{|c|c|c|c|c|c|c|c|}
\hline & \multicolumn{3}{|c|}{ Canopy width $(\mathrm{cm})$ at height of } & \multirow[t]{2}{*}{$\mathrm{CH}(\mathrm{cm})$} & \multirow[t]{2}{*}{$\mathrm{BR}(\mathrm{cm})$} & \multirow[t]{2}{*}{ LAI } & \multirow[t]{2}{*}{$\operatorname{TRV}\left(\mathrm{m}^{3} \mathrm{ha}^{-1}\right)$} \\
\hline & $100 \mathrm{~cm}$ & $150 \mathrm{~cm}$ & $300 \mathrm{~cm}$ & & & & \\
\hline $\mathrm{SSP} / 1$ & $75-90$ & $80-95$ & $25-35$ & $300-320$ & 280 & $0.09-0.12$ & $8,100-8,750$ \\
\hline $\mathrm{SSP} / 2$ & $90-100$ & $100-110$ & $30-40$ & $320-340$ & 280 & $2.62-2.76$ & $10,100-10,850$ \\
\hline MSP/1 & $100-120$ & $120-130$ & $30-40$ & $310-330$ & 380 & $0.11-0.14$ & $9,850-10,400$ \\
\hline $\mathrm{MSP} / 2$ & $125-140$ & $140-160$ & $40-50$ & $350-385$ & 380 & $3.12-3.26$ & $11,600-12,100$ \\
\hline
\end{tabular}

$C H$ canopy height, $B R$ distance between tree rows, $L A I$ leaf area index, $T R V$ tree row volume, $S S P$ super spindle, $M S P$ modified slender spindle trees

Table 2 Parameters of spray application during test performance

\begin{tabular}{lllllccc}
\hline & $\begin{array}{l}\text { Type of } \\
\text { nozzle }\end{array}$ & \multicolumn{2}{l}{$\begin{array}{l}\text { Operating pressure } \\
(\mathrm{kPa})\end{array}$} & $\begin{array}{l}\text { Nozzle flow rate } \\
\left(\mathrm{L} \mathrm{min}{ }^{-1}\right)\end{array}$ & $\begin{array}{l}\text { No. of } \\
\text { nozzles }\end{array}$ & $\begin{array}{l}\text { Driving speed } \\
\left(\mathrm{km} \mathrm{h}^{-1}\right)\end{array}$ & $\begin{array}{l}\text { Spray volume } \\
\left.(\mathrm{L} \mathrm{ha})^{-1}\right)\end{array}$ \\
\hline SSP & ATR orange & $480 \pm 10$ & $0.97 \pm 0.1$ & 12 & 5.0 & $499 \pm 10$ & $\begin{array}{l}\text { Droplet VMD } \\
(\mu \mathrm{m})\end{array}$ \\
SSP & ATR red & $1,010 \pm 10$ & $1.94 \pm 0.1$ & 12 & 10.0 & $498 \pm 10$ & $165 \pm 5$ \\
SSP & TVI 80-015 & $1,140 \pm 10$ & $1.17 \pm 0.1$ & 10 & 5.0 & $501 \pm 10$ & $460 \pm 15$ \\
SSP & TVI 80-020 & $1,770 \pm 10$ & $1.94 \pm 0.1$ & 12 & 10.0 & $498 \pm 10$ & $450 \pm 15$ \\
MSP & ATR orange & $900 \pm 10$ & $1.32 \pm 0.1$ & 12 & 5.0 & $500 \pm 10$ & $155 \pm 5$ \\
MSP & ATR grey & $1,640 \pm 10$ & $2.62 \pm 0.1$ & 12 & 10.0 & $500 \pm 10$ & $170 \pm 5$ \\
MSP & TVI 80-015 & $1,460 \pm 10$ & $1.32 \pm 0.1$ & 12 & 5.0 & $499 \pm 10$ & $465 \pm 15$ \\
MSP & TVI 80-025 & $1,580 \pm 10$ & $2.28 \pm 0.1$ & 14 & 10.0 & $499 \pm 10$ & $470 \pm 15$ \\
\hline
\end{tabular}

SSP super spindle orchard, MSP modified slender spindle orchard

system (super spindle and modified slender spindle), 3vegetation period (spring or summer), 4-sprayer travel speed $\left(5\right.$ and $10 \mathrm{~km} \mathrm{~h}^{-1}$ ) and 5-droplet size (fine droplets VMD 150-170 $\mu \mathrm{m}$ and coarse droplets VMD 450-470 $\mu \mathrm{m}$ ). The VMD (droplet volume median diameter) refers to a value where $50 \%$ of the total volume or mass of liquid sprayed is made up of droplets larger than this value, and $50 \%$ made up of droplets smaller than this value (Matthews 2000).

The analysis of variance for repeated measures (ANOVA) was performed for factorial design by using the Statgraphics Centurion XVI software (StatPoint Technologies, Inc. Warrenton, USA). The multiple comparison LSD test (Fisher's least significant difference; $P<0.05$ ) was used to determine the significance of differences among drift means. A standard deviation (SD) was calculated for all means. The homogeneity of variances was tested prior to analysis, and there was no need for data transformation.

Tested sprayers, nozzles and operating parameters

Two sprayers that were driven by tractor power take-off were tested. The parameters of spray application (type of nozzles, operating pressure, flow rates and droplet size) are presented in Table 2. The first was the Unigreen Turboteuton $(4+4)$ radial-fan sprayer produced by the Unigreen company (Italy) (Fig. 1). Air is fed to spouts on both sites of the sprayer $(4+4$ spouts). The air jets generated by the radial fan had a velocity of $52.5-53.5 \mathrm{~m} \mathrm{~s}^{-1}$ measured at a $20 \mathrm{~cm}$ distance from the edge of the spout. It was determined by using a vane anemometer Schiltknecht MiniAir20 (Schiltknecht Messtechnik AG, 8625 Gossau/ZH, Switzerland). The spouts can be adjusted to direct the air into the desired layer of the tree crown. In our case, the spouts were directed perpendicularly to the tree canopy. During the tests, the fan capacity was $19.500 \mathrm{~m}^{3} \mathrm{~h}^{-1}$. This sprayer will be referred to as radial sprayer.

The Agromehanika 400 ENU sprayer (Agromehanika, Kranj, Slovenia) is a typical axial sprayer with a fan $(\Phi$ $825 \mathrm{~mm}$ ) (Fig. 2). The ENU acronym stands for the air jet deflector equipped sprayer. This sprayer will be referred to as standard axial sprayer. The air flow rate capacity of the sprayer was set to $20.100 \mathrm{~m}^{3} \mathrm{~h}^{-1}$, and its fan produced a jet with a velocity of $31.3-31.7 \mathrm{~m} \mathrm{~s}^{-1}$ at $20 \mathrm{~cm}$ distance from the edge of the housing (Table 3 ).

The fan settings (rotation speed and capacity) of both sprayers remained the same for all treatments. The position and structure of the sprayers can be seen in Fig. 1.

Standard ATR hollow-cone and TVI hollow-cone driftreducing nozzles produced by the Albuz company (SaintGobain, France) were used for all the tests. The ATR and TVI acronyms were appointed by the manufacturer Albuz (see http://www.albuz-spray.com/en/busesenceramiqueceramicnozzles-boquillasdeceramica). ATR nozzles 


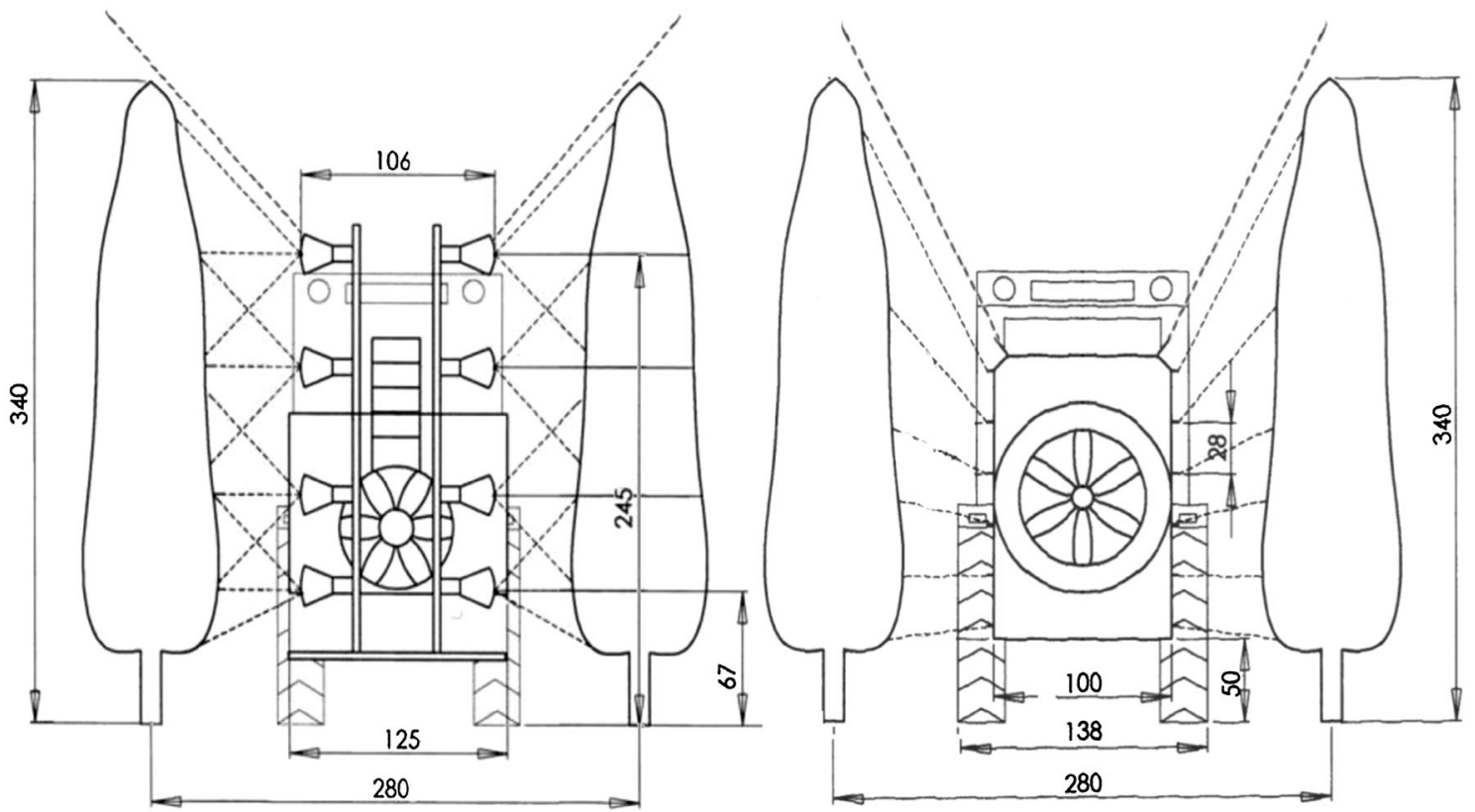

Fig. 1 Comparison of tested sprayers (radial-fan, left and axial-fan sprayer, right) and their positions between the tree rows in a super spindle orchard. Measures are given in centimetre

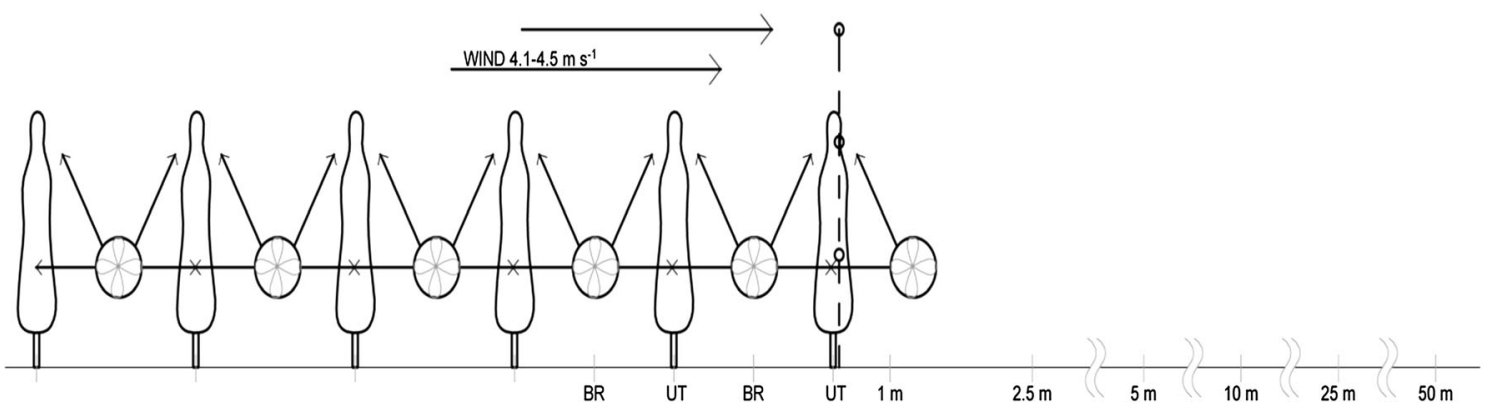

Fig. 2 Layout of trial for assessment of ground deposit of drifted spray

produce fine droplets, which are prone to drift, and TVI nozzles produce large drops, which do not drift out of the spraying zone. The operating pressures during the test were set in a such way that the nozzles were producing either fine droplets (VMD 150-170 $\mu \mathrm{m}$ ) or coarse droplets (VMD $450-470 \mu \mathrm{m}$ ). The data on the VMD (droplet volume median diameter) values for a specific operating pressure were provided by the Albuz company.

\section{Conduct of field assessments of drift}

The spraying zone for each of the two orchard blocks had a dimension of $80 \mathrm{~m} \times 20 \mathrm{~m}$. On the 50-m-long spraying route, six passes of the tractor were repeated for each individual assessment (see Fig. 2). The test was performed in conditions with heavy wind to get enough deposit on the collectors, which had a small collecting surface; thus, a windy day was awaited to have a suitable wind speed between 4 and $5 \mathrm{~m} \mathrm{~s}^{-1}$, with a constant direction perpendicular to the tree rows of the test orchard. The wind conditions during the spring (BBCH 15, before blooming) and summer periods (BBCH 78-79, fruit about $80 \%$ final size) were similar. Tree growth stage was described according to the BBCH scale (Meier 1997). During each spray application, the meteorological date were recorded by the AMES RVM 96C meteorological station and using the AMES VMT 107 A wind speed and wind direction sensor (Ames, Slovenia). The wind speed was measured at heights of 150 and $300 \mathrm{~cm}$ (inside the last tree row) and also at $450 \mathrm{~cm}$ (above the last tree row). The sensors were mounted on a pillar placed in the last row of the test zone (see Fig. 3). The wind speed and direction remained stable long enough to ensure that conditions were comparable during all assessments. All the tests were made by spraying plots of six tree rows with a solution of water and yellow Tartrazine E102 $\left(10 \mathrm{~g} \mathrm{~L}^{-1}\right)$ (ETOL, Celje, Slovenia) and 
Table 3 Data about the wind speed (WS), relative air humidity (RH) and air temperature (AT) at three different heights during test performance

\begin{tabular}{|c|c|c|c|c|c|c|}
\hline \multirow[t]{2}{*}{ Date } & \multicolumn{3}{|l|}{ Last row } & \multicolumn{3}{|c|}{$25 \mathrm{~m}$ downwind from last row } \\
\hline & $150 \mathrm{~cm}$ & $300 \mathrm{~cm}$ & $450 \mathrm{~cm}$ & $150 \mathrm{~cm}$ & $300 \mathrm{~cm}$ & $450 \mathrm{~cm}$ \\
\hline April 25 & BBCH 15 & & & & & \\
\hline WS $\left(\mathrm{m} \mathrm{s}^{-1}\right)$ & $3.2-3.7$ & $3.3-3.9$ & $4.2-4.7$ & $3.8-4.1$ & $3.9-4.3$ & $4.7-5.5$ \\
\hline $\mathrm{RH}(\%)$ & $67.5-67.9$ & $64.5-65.9$ & $63.9-64.7$ & $65.5-65.7$ & $64.9-65.3$ & $63.9-64.6$ \\
\hline $\mathrm{AT}\left({ }^{\circ} \mathrm{C}\right)$ & $20.2-21.7$ & $20.4-21.9$ & $20.9-22.4$ & $20.9-21.5$ & $21.2-21.9$ & $21.3-22.2$ \\
\hline August 16 & $\mathrm{BBCH} 78$ & & & & & \\
\hline WS $\left(\mathrm{m} \mathrm{s}^{-1}\right)$ & $1.4-1.8$ & $2.2-2.4$ & $4.1-4.8$ & $1.9-2.1$ & $2.9-3.7$ & $4.2-5.7$ \\
\hline $\mathrm{RH}(\%)$ & $61.2-63.7$ & $60.3-61.9$ & $58.9-60.7$ & $61.2-63.7$ & $60.3-61.9$ & $58.9-60.7$ \\
\hline $\mathrm{AT}\left({ }^{\circ} \mathrm{C}\right)$ & $23.2-23.7$ & $24.3-24.9$ & $24.2-24.7$ & $23.2-23.7$ & $24.3-24.9$ & $24.2-24.7$ \\
\hline
\end{tabular}

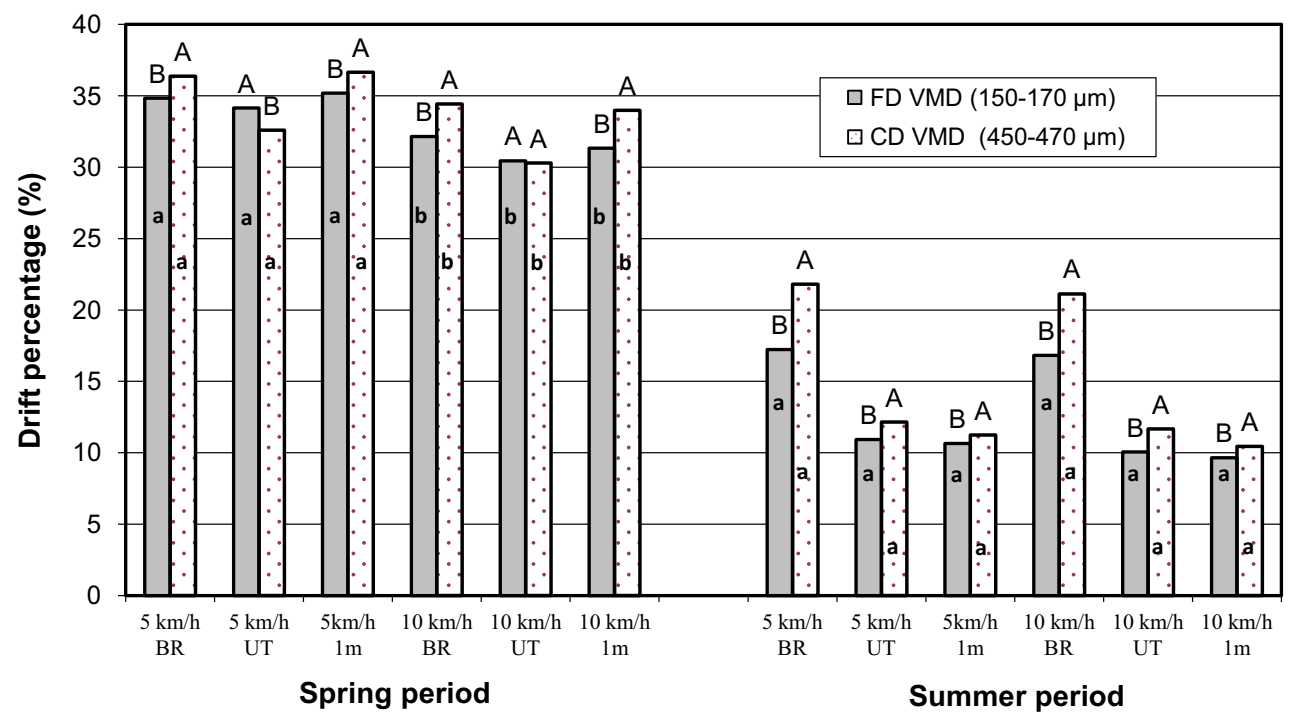

Fig. 3 Drift percentages (\%) in relation to droplet size (FD-fine droplets and $\mathrm{CD}$-coarse droplets), sprayer travel speeds (5 or $10 \mathrm{~km} \mathrm{ha}^{-1}$ ) and position (UT-under trees and BR-between tree rows). Means marked with the same capital letters do not differ significantly, according to the LSD test $(P<0.05)$, when comparing the effect of droplet size (FD vs. CD) at a specific speed and position.

plastic trays $(20 \times 30 \mathrm{~cm})$ served as drift collectors. These were placed horizontally on the cut grass in five parallel rows and were oriented perpendicularly to the last tree row of the orchard, at distances of $0,1,2.5,5,10,25$ and $50 \mathrm{~m}$ (see Fig. 2). Other plastic trays were also placed exactly in the middle between the tree rows and under the trees.

The trays were collected immediately after the spraying and placed in black cardboard boxes to prevent access to sunlight and photochemical decomposition of the dye. The Tartrazine dye was extracted from the trays by filling them with distilled water and leaving them to soak for $30 \mathrm{~min}$.

The concentration of tartrazine in the extracted water was determined using a Varian Carry 50 spectrophotometer (Varian Inc., USA), performing readings at a 430-nm
Means marked with the same small letters do not differ significantly, according to the LSD test $(P<0.05)$, when comparing the effect of travel speed ( 5 vs. $10 \mathrm{~km} \mathrm{~h}^{-1}$ ) at a specific position (UT vs. UT, BR vs. BR and 1 vs. $1 \mathrm{~m}$ ) and specific droplet size (FD vs. FD and CD vs. CD)

absorbance level. From the solution concentrations obtained by photospectrometeric analysis, the amount of spray drift collected by the trays was calculated. Measured ground spray deposit (Md) on the collectors was expressed in $\mu \mathrm{g} \mathrm{cm}^{-2}$. Drift ( $D \%$ ) was expressed as drift percentage and calculated as the ratio between measured Tartrazine deposit (Md) and theoretical Tartrazine deposit (Td) according to the Yarpuz-Bozdogan and Bozdogan method (2009). The Td was calculated according to Eq. 1 and $D$ (\%) according to Eq. 2, where sv refers to spray volume $\left(5001 \mathrm{ha}^{-1}\right)$, dc to tartrazine dye concentration $\left(10 \mathrm{~g} \mathrm{~L}^{-1}\right)$ and sa to sprayed area $\left(10.000 \mathrm{~m}^{-2}\right)$ :

$\operatorname{Td}\left(\mu \mathrm{g} \mathrm{cm}^{-2}\right)=\left(\frac{\mathrm{sv} x \mathrm{dc}}{\mathrm{sa}}\right) \cdot 0.0001$ 
Table 4 Analysis of the statistical significance ( $P$ values) of trial factors influencing the percentage of spray drift in spraying the apple orchard

\begin{tabular}{|c|c|c|c|c|c|c|c|c|}
\hline & \multicolumn{8}{|c|}{ Distance from the last orchard row } \\
\hline & $\mathrm{BR}$ & UT & $1 \mathrm{~m}$ & $2.5 \mathrm{~m}$ & $5 \mathrm{~m}$ & $10 \mathrm{~m}$ & $25 \mathrm{~m}$ & $50 \mathrm{~m}$ \\
\hline \multicolumn{9}{|l|}{ Main factors } \\
\hline A: tree growth stage & $* * *$ & $* * *$ & $* * *$ & $* * *$ & $* * *$ & $* * *$ & $* * *$ & 0.007 \\
\hline B: tree training system & $* * *$ & $* * *$ & $* * *$ & $* * *$ & $* * *$ & $* * *$ & $* * *$ & 0.008 \\
\hline C: sprayer travel speed & $* * *$ & $* * *$ & $* * *$ & $* * *$ & $* * *$ & $* * *$ & $* * *$ & 0.040 \\
\hline D: type of sprayer & $* * *$ & $* * *$ & $* * *$ & $* * *$ & $* * *$ & $* * *$ & $* * *$ & 0.009 \\
\hline E: droplet size & 0.004 & 0.030 & $* * *$ & $* * *$ & $* * *$ & $* * *$ & $* * *$ & $* * *$ \\
\hline \multicolumn{9}{|l|}{ Interactions } \\
\hline $\mathrm{A} \times \mathrm{B}$ & $* * *$ & 0.031 & 0.036 & $* * *$ & $* * *$ & $* * *$ & $* * *$ & 0.009 \\
\hline $\mathrm{A} \times \mathrm{C}$ & $* * *$ & $* * *$ & $* * *$ & $* * *$ & $* * *$ & $* * *$ & $* * *$ & 0.035 \\
\hline$A \times D$ & 0.433 & $* * *$ & $* * *$ & 0.736 & 0.452 & $* * *$ & $* * *$ & 0.038 \\
\hline$A \times E$ & 0.110 & 0.239 & $* * *$ & $* * *$ & $* * *$ & $* * *$ & $* * *$ & 0.007 \\
\hline $\mathrm{B} \times \mathrm{C}$ & 0.412 & 0.430 & 0.819 & 0.496 & 0.006 & 0.008 & $* * *$ & 0.004 \\
\hline$B \times D$ & $* * *$ & $* * *$ & $* * *$ & $* * *$ & $* * *$ & $* * *$ & $* * *$ & $* * *$ \\
\hline$B \times E$ & 0.908 & 0.965 & 0.930 & $* * *$ & $* * *$ & $* * *$ & $* * *$ & 0.009 \\
\hline $\mathrm{C} \times \mathrm{D}$ & 0.003 & 0.008 & $* * *$ & $* * *$ & $* * *$ & $* * *$ & $* * *$ & 0.049 \\
\hline $\mathrm{C} \times \mathrm{E}$ & 0.527 & 0.010 & 0.194 & 0.012 & $* * *$ & $* * *$ & $* * *$ & 0.347 \\
\hline $\mathrm{D} \times \mathrm{E}$ & $* * *$ & $* * *$ & $* * *$ & $* * *$ & 0.003 & 0.006 & 0.003 & 0.263 \\
\hline
\end{tabular}

$B R$ between tree rows, $U T$ under trees

*** Significant at $P<0.001$

$D(\%)=\frac{\mathrm{Md}}{\mathrm{Td}} \cdot 100$

\section{Results and discussion}

Statistical significance of factors tested

The results of the ANOVA test for factorial design (five factors and their interaction) are presented in Table 4. As can be seen, all tested factors (type of sprayer, tree training system, tree growth stage, sprayer travel speed and droplet size) had a significant effect on the spray drift percentage. Besides, the majority of first-order interactions were significant at all positions analysed. This proves that sprayer travel speed influences drift significantly; furthermore, the interactive effects differ in magnitude for applications carried out with different combinations of sprayer, training system, droplet size and vegetation period. In particular, interaction between the type of sprayer and the type of tree training system was highly significant (see Table 4; BxD). Interaction between the tree growth stage and the travel speed of the sprayer was also highly significant. The interaction between the tree training system and the sprayer travel speed was significant only from $5.0 \mathrm{~m}$ onwards, which means that the effect of increased travel speed on the spray drift percentage was similar for both training systems.
Results of drift assessment during spring applications

The spring applications were performed at the beginning of the blooming stage (BBCH 15) when the trees had low spray filtering capacity. During that period, we expected high levels of drift. The trial was performed under a strong side wind $\left(4-4.5 \mathrm{~m} \mathrm{~s}^{-1}\right)$. Tables 5 and 6 present the spray drift percentages for the specific positions where the Tartrazine tracer ground deposits were measured. Table 5 contains data for small droplet spraying (VMD 150-170 $\mu \mathrm{m}$ ) and Table 6 for spraying with coarse droplets (VMD $450-470 \mu \mathrm{m}$ ).

Firstly, it was noticeable that the drift was reduced by more than $50 \%$ at most of the analysed positions outside the orchard whenever coarse spraying was used. That result was expected because it is well known from the literature that drift can be reduced by increasing the droplet size (Cross et al. 2001; Yarpuz-Bozdogan and Bozdogan 2009). The ground deposits inside the orchard (BR-between rows) during coarse spraying were higher for both sprayer types, travel speeds and tree training systems when compared to fine spraying (compare BR data from Tables 5, 6). A separate presentation of data of ground deposits in relation to the sprayer travel speed and droplet size can be seen in Fig. 3. Data presented in Fig. 3 are averages of data combined for both types of sprayers. For example, in the super spindle orchard $\left(5 \mathrm{~km} \mathrm{~h}^{-1}\right.$ speed, fine droplets) the BR deposit amounted to $42.9 \%$, while during spraying 
Table 5 Mean drift percentages ( $\% \pm \mathrm{SD} ; n=20)$ at specific positions in relation to the type of sprayer, tree training system and sprayer travel speed when spraying with fine droplets (VMD 150-170 $\mu \mathrm{m}$ ) during spring assessment (April 25, BBCH 15)

\begin{tabular}{|c|c|c|c|c|c|c|}
\hline \multirow[t]{2}{*}{ Sampling position } & \multicolumn{2}{|c|}{ Type of sprayer } & \multicolumn{2}{|c|}{ Tree training system } & \multicolumn{2}{|l|}{ Driving speed } \\
\hline & Axial & Radial & SSP & MSP & $5 \mathrm{~km} \mathrm{~h}^{-1}$ & $10 \mathrm{~km} \mathrm{~h}^{-1}$ \\
\hline $\mathrm{BR}$ & $37.64 \pm 2.15$ & $29.33 \pm 1.16$ & $35.06 \pm 1.73$ & $31.90 \pm 1.73$ & $34.83 \pm 0.48$ & $32.14 \pm 0.22$ \\
\hline UT & $33.78 \pm 0.84$ & $30.83 \pm 0.47$ & $33.55 \pm 1.05$ & $31.05 \pm 0.93$ & $34.15 \pm 1.28$ & $30.45 \pm 1.12$ \\
\hline $1 \mathrm{~m}$ & $34.78 \pm 1.55$ & $31.64 \pm 1.26$ & $35.18 \pm 1.90$ & $31.33 \pm 1.84$ & $35.18 \pm 1.20$ & $31.33 \pm 1.30$ \\
\hline $2.5 \mathrm{~m}$ & $22.60 \pm 1.47$ & $20.34 \pm 0.34$ & $24.40 \pm 2.23$ & $18.54 \pm 1.86$ & $23.10 \pm 1.74$ & $19.84 \pm 2.21$ \\
\hline $5 \mathrm{~m}$ & $15.94 \pm 0.17$ & $13.88 \pm 0.53$ & $17.53 \pm 2.96$ & $12.29 \pm 1.20$ & $16.63 \pm 0.37$ & $13.18 \pm 1.04$ \\
\hline $10 \mathrm{~m}$ & $8.71 \pm 0.35$ & $7.45 \pm 0.49$ & $10.01 \pm 1.67$ & $6.15 \pm 0.53$ & $9.78 \pm 1.07$ & $6.37 \pm 1.22$ \\
\hline $25 \mathrm{~m}$ & $4.21 \pm 0.41$ & $3.27 \pm 0.32$ & $5.18 \pm 1.34$ & $2.30 \pm 0.43$ & $4.97 \pm 1.09$ & $2.51 \pm 0.37$ \\
\hline $50 \mathrm{~m}$ & $0.56 \pm 0.04$ & $0.45 \pm 0.06$ & $0.69 \pm 0.37$ & $0.34 \pm 0.17$ & $0.67 \pm 0.23$ & $0.31 \pm 0.19$ \\
\hline
\end{tabular}

$S S P$ super spindle trees, $M S P$ modified slender spindle trees, $B R$ between tree rows, $U T$ under trees

Table 6 Mean drift percentages $(\% \pm \mathrm{SD} ; n=20)$ at specific positions in relation to the type of sprayer, tree training system and sprayer travel speed when spraying with fine droplets (VMD 150-170 $\mu \mathrm{m}$ ) during spring assessment (April 25, BBCH 15)

\begin{tabular}{|c|c|c|c|c|c|c|}
\hline \multirow[t]{2}{*}{ Sampling position } & \multicolumn{2}{|c|}{ Type of sprayer } & \multicolumn{2}{|c|}{ Tree training system } & \multicolumn{2}{|l|}{ Driving speed } \\
\hline & Axial & Radial & SSP & MSP & $5 \mathrm{~km} \mathrm{~h}^{-1}$ & $10 \mathrm{~km} \mathrm{~h}^{-1}$ \\
\hline $\mathrm{BR}$ & $41.03 \pm 3.30$ & $29.78 \pm 2.75$ & $37.98 \pm 1.87$ & $33.83 \pm 1.06$ & $36.38 \pm 0.43$ & $34.43 \pm 0.21$ \\
\hline UT & $33.98 \pm 1.76$ & $28.93 \pm 1.56$ & $32.70 \pm 2.30$ & $30.20 \pm 2.87$ & $32.60 \pm 4.06$ & $30.30 \pm 3.75$ \\
\hline $1 \mathrm{~m}$ & $38.99 \pm 2.75$ & $31.65 \pm 3.05$ & $37.43 \pm 2.13$ & $33.21 \pm 1.87$ & $36.66 \pm 2.75$ & $33.98 \pm 2.07$ \\
\hline $2.5 \mathrm{~m}$ & $18.69 \pm 3.50$ & $11.86 \pm 1.27$ & $19.15 \pm 2.05$ & $11.40 \pm 2.76$ & $16.21 \pm 1.01$ & $14.34 \pm 0.72$ \\
\hline $5 \mathrm{~m}$ & $8.11 \pm 1.06$ & $5.68 \pm 0.98$ & $8.50 \pm 1.07$ & $5.28 \pm 0.99$ & $7.94 \pm 0.65$ & $5.84 \pm 0.45$ \\
\hline $10 \mathrm{~m}$ & $4.53 \pm 1.02$ & $2.65 \pm 0.65$ & $5.01 \pm 1.01$ & $2.17 \pm 1.11$ & $4.62 \pm 0.37$ & $2.56 \pm 0.50$ \\
\hline $25 \mathrm{~m}$ & $2.14 \pm 0.76$ & $0.90 \pm 0.33$ & $2.22 \pm 0.94$ & $0.82 \pm 0.65$ & $2.25 \pm 0.08$ & $0.79 \pm 0.56$ \\
\hline $50 \mathrm{~m}$ & $0.27 \pm 0.06$ & $0.11 \pm 0.02$ & $0.28 \pm 0.12$ & $0.10 \pm 0.07$ & $0.26 \pm 0.04$ & $0.09 \pm 0.03$ \\
\hline
\end{tabular}

SSP super spindle trees, MSP modified slender spindle trees, $B R$ between tree rows, $U T$ under trees

with the coarse droplets, it amounted to $45.9 \%$ at the same speed. These results agreed with the findings of other researchers (Derksen et al. 2007; Sehsah 2007), who also found that coarse spraying resulted in higher ground deposits inside the orchard when compared to spraying with fine sprays. This is a negative effect of coarse spraying. The same was observed for drift at $1 \mathrm{~m}$ distance from the last row of the orchard during applications with the axial sprayer (see Fig. 3; $1 \mathrm{~m}$ ). It is known from the literature that at a short distance from the orchard edge, drift values determined for spraying with coarse droplets could be equal to, or even higher than during spray consisting of fine droplets (Heijne et al. 2002). Heijne et al. (2002) did a comparison of the drift rate between standard and the drift-reducing (air-inclusion) nozzles and found that the drift-reducing nozzles (Albuz TDM nozzle) did not reduce spray loss on the ground in a range of 3-7 $\mathrm{m}$ from the last tree row when compared to spray loss determined during spraying with the fine droplets discharged from the standard Albuz ATR nozzles. The results of this study partially match with those of Heijne et al. (2002) for the range of $1 \mathrm{~m}$ but not for other positions analysed. The findings mentioned above show the weak point of coarse droplet spraying and suggest that coarse droplet spraying does not solve the problem of protecting sensitive areas (water courses, walking paths, adjacent vegetation, etc) nearby the orchard edge. If the BR ground deposit increases due to the increase in droplet size, then the ecological benefits of coarse droplet spraying are poorer. The exo-drift is reduced without a doubt, but at the cost of increasing the endo-drift, when the soil deposit inside the orchard (endo-drift) increases the possibilities for pesticide surface run-off or leaching also increase, as reported by Ross et al. (1997). This is especially true for orchards that have a wide herbicide-treated belt under the trees (bare soil), which are established on slopes, on gravel and on sandy soils or are irrigated (Ross et al. 1997). The results show the complexity of the interactions among the parameters of spraying. The use of drift-reducing nozzles as a drift reduction measure without understanding the 
interactions with other factors (structure of orchard and application equipment settings) does not provide as high a level of environmental protection as usually expected.

When comparing the average spray drift percentage for 5 and $10 \mathrm{~km} \mathrm{~h}^{-1}$ travel speeds, we can see that increasing the sprayer travel speed decreases the spray drift percentage at most of positions inside and outside the orchard (compare data for 5 and $10 \mathrm{~km} \mathrm{~h}^{-1}$ speed in Tables 5, 6). For example, increasing the travel speed from 5 to $10 \mathrm{~km} \mathrm{~h}^{-1}$ decreased the average drift at $25 \mathrm{~m}$ during fine spraying by $49.5 \%$ (from 4.97 to $2.51 \%$ ) and by $63.6 \%$ (from 2.2 to $0.8 \%$ ) during coarse spraying (see Tables 5, 6; $25 \mathrm{~m}$ ). These results are similar to those obtained by Sehsah (2007), who found that a travel speed of $12 \mathrm{~km} \mathrm{~h}^{-1}$ reduced drift by $95.1 \%$ compared to travel speed of $6 \mathrm{~km} \mathrm{~h}^{-1}$ by using Albuz AVI80015 nozzles, which are comparable to the Albuz TVI80015 nozzle tested in our trials. Additionally, Fox et al. (1985) and Walklate et al. (1996) found that sprayer travel speed induced bending of the air jet, which reduced spray drift and increased total spray deposition on the trees.

The average spray drift percentages determined during spraying with the radial-fan sprayer were significantly lower at most of positions than in the case of spraying with the axial-fan sprayer in both spray droplet size categories (fine or coarse). The same type of nozzle was mounted in both sprayers (both fine and coarse), and the initial sizes of droplets at air outlet from both sprayers were the same. For example, during the fine spraying, drift at $25 \mathrm{~m}$ distance amounted to $4.21 \%$ during axial-fan spraying and $22.3 \%$ less $(3.27 \%$ ) during radial-fan spraying (see Table 5; $25 \mathrm{~m}$ ). In contrast, in the case of course spraying, drift amounted to $2.14 \%$ during axial-fan spraying and to $0.90 \%$ during radial-fan spraying, which represented $57.9 \%$ less drift (see Table 6; $25 \mathrm{~m}$ ). The main reason for these differences between the two sprayers lies in the orientation of air jet and stability of the kinetic energy of the sprayer air jet. Differences among air jet characteristic of sprayers using different fan technologies can nowadays be successfully described by using the three-dimensional computational fluid dynamics modelling (CDF) based on the Lagrangian particle transport concept. Some CDF models for describing the differences in kinetics of air jets produced by axial-fan or radial-fan sprayers with the aim to support the technical improvements at drift reduction are being developed (Delele et al. 2007; Endalew et al. 2011, 2012). During the development of the mentioned models, the same type of ATR nozzle was used as in our research and that showed that the droplet trajectories and the disintegration pattern of droplets sprayed in the air jets of axial or radial fan are different because of the differences in initial air velocities, shape of plum and in the pattern of air plum kinetic energy dispersal and decline. Differences are usually visually presented by vertical profiles of the Cartesian velocity components and by 3-D plots of air velocity isosurfaces (see Endalew et al. 2012). This research shows that the kinetic energy of axial-fan sprayer plum at the top of the canopy and above it is significantly higher than in the case of radial-fan sprayers with spouts and that also the density of droplets in the air jet above the canopy is higher in the case of axial-fan sprayers. This directly reflects in higher off-target deposition of axial-fan sprayers. The positions and orientations of the nozzles are also different when we compare the standard settings of an axial-fan or radial-fan sprayer. Differences in disintegration patterns and consequently in droplet mass density per unit volume were proven and well visualised during the research work of Delele et al. (2007). Axial sprayers usually have a higher droplet mass density above tree canopies, when compared to radial sprayers with air spouts operating at equal air volume capacity.

In the case of the radial-fan sprayer, in our trial, we used the air jet that could be directed much more accurately than the axial-fan sprayer (jet comparison of both sprayers in Fig. 1). In the super spindle orchards with narrow tree distances, as at the test site, the air jet needed to be angled steeply to the top of the trees; otherwise, low spray deposits would be recorded at the top layer of the trees. This technical weakness of axial sprayers is well known. It promotes more drift, especially if we have tall trees $(3.5 \mathrm{~m})$ planted at a very narrow row distances $(2.8 \mathrm{~m})$. For the sake of good biological efficacy of pesticides at tree top positions, we risk a significantly higher level of orchard adjacent area pollution. During the axial-fan spraying in our experiment, the air jet angle was much steeper than during radial-fan spraying; thus, the part of the air stream missing the top of the green wall was relatively higher when compared to the same effect during radial-fan spraying. The main reason is traceable to the axial-fan sprayer's air characteristics, with its large volume and low velocity. This is a contrast to the radial-fan sprayer, which usually has a lower air volume and higher air velocity. Thus, the jets produced by the axial sprayers penetrate the tree canopies more efficiently and maintain the initial air direction much longer than those from the radial sprayers (Cross et al. 2003). These differences are commonly known and have been described by several authors (Derksen and Gray 1995; Cross et al. 2003; Świechowski et al. 2004).

The air flow rate of the axial-fan sprayer $\left(20.100 \mathrm{~m}^{3} \mathrm{~h}^{-1}\right)$ was not much higher than that of the radial fan $\left(19.500 \mathrm{~m}^{3} \mathrm{~h}^{-1}\right)$; it was therefore assumed that the air jet orientation had a more important influence on the determined drift than the difference in the air flow rate.

When comparing the average spray drift percentage (Tables 5,6) during the spring trial on the super spindle (SSP) and the modified spindle (MSP) orchards, it could be seen that the training system had a significant impact on the 


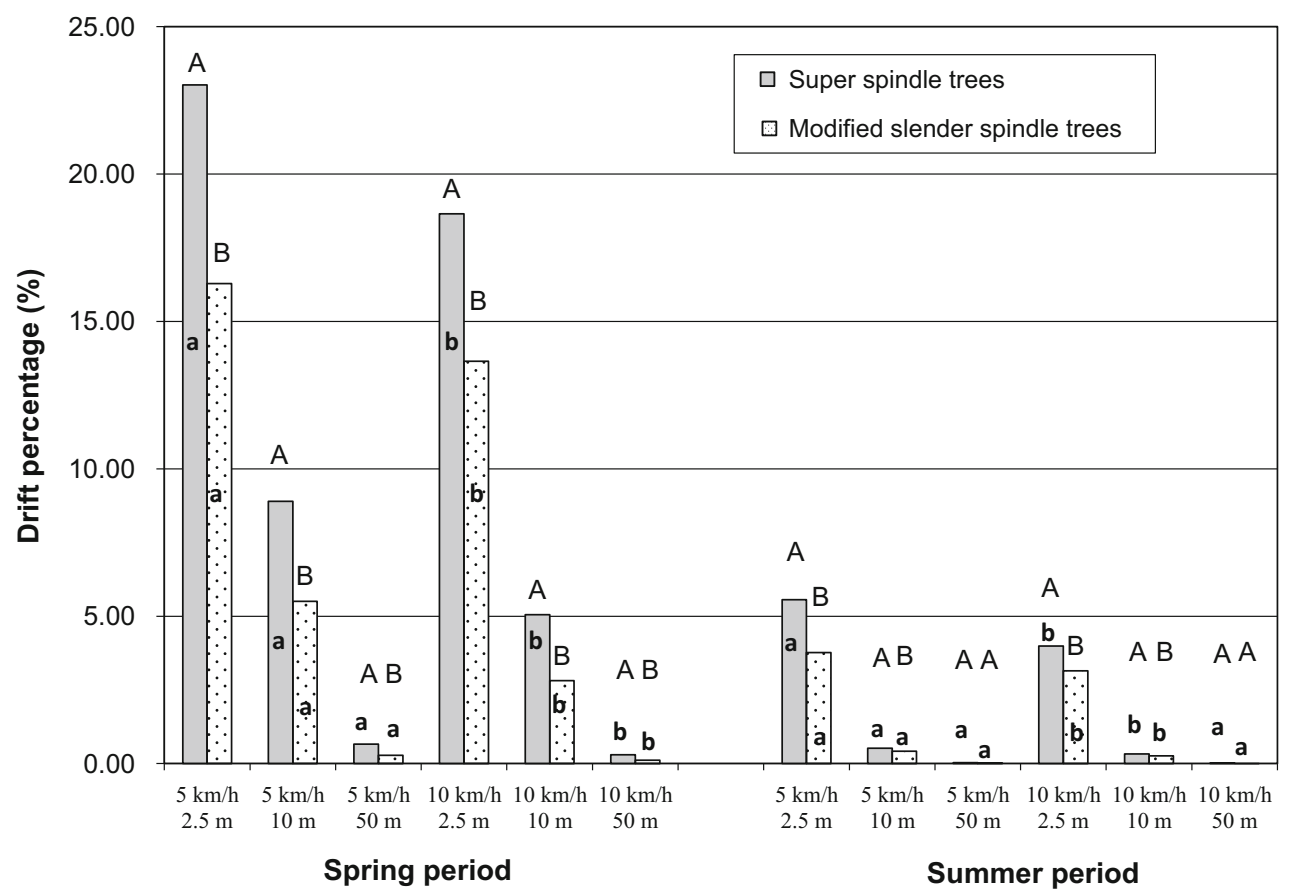

Fig. 4 Drift percentages (\%) in relation to type of tree training system (super spindle or modified slender spindle), travel speeds (5 or $\left.10 \mathrm{~km} \mathrm{~h}^{-1}\right)$ and position $(2.5,10$ and $50 \mathrm{~m}$ from the orchard edge). Means marked with the same capital letters do not differ significantly, according to the LSD test $(P<0.05)$, when comparing the effect of

amount of spray drift (see comparisons between SSP and MSP in Tables 5, 6; Fig. 4). The canopy of the MSP trees had greater filtering capacity than the canopy of the SSP trees even at an early development stage; the drift values were therefore lower in the MSP orchard than in the SSP orchard at all positions analysed (see Table 5 SSP vs. MSP; Fig. 4). For example, during fine spraying of the SSP trees, drift amounted to $5.18 \%$ at a distance of $25 \mathrm{~m}$ and to only $2.30 \%$ for the MSP trees. During the coarse spraying trial, drift amounted to $2.22 \%$ for the SSP trees at a distance of $25 \mathrm{~m}$, and only $0.82 \%$ for the MSP trees (see Table 6; $25 \mathrm{~m}$ SSP vs. MSP). Thus, during spraying with coarse droplets in the MSP orchard, drift at a distance of $25 \mathrm{~m}$ was $63.6 \%$ lower than in the SSP orchard (compare Tables 5, 6; MSP; $25 \mathrm{~m}$ ). Differences in deposits between the tree training systems lead us to the conclusion that the adaptation of tree structures has the potential to reduce drift. Trees of border rows of orchards should be trained in a different way as the ones inside the orchard to increase their filtering capacity. The combination of high trees (more than $3 \mathrm{~m}$ ) and very narrow row distances (less than $3 \mathrm{~m}$ ) facilitates the spray drift especially when using standard axial sprayers. Similar findings were also presented by Wenneker and van de Zande 2008, Triloff 2011 and Bondesan et al. 2012. With certain tree training systems, we can predispose orchards to become important tree training systems (super spindle vs. modified spindle) at a specific speed and position. Means marked with the same small letters do not differ significantly, according to the LSD test $(P<0.05)$, when comparing the effect of travel speed (5 vs. $\left.10 \mathrm{~km} \mathrm{~h}^{-1}\right)$ at a specific position ( 2.5 vs. $2.5 \mathrm{~m}$, etc).

pollution points. Sophisticated CDF models for describing influences of tree training systems on pesticide drift are being developed (Hendrickx et al. 2012). They will provide fruit producers with information on the adaptation of tree training systems (especially on the optimal ratio between canopy height and row distance) to different types of sprayers and about the possibilities of manufacturers adapting sprayer air outlets to tree canopies. A lot of measurements in actual orchard environments such as ours are still needed to validate models.

Results of drift assessments during summer applications

The results of the drift assessments during the summer period are presented in Tables 7 and 8. During the summer test, a somewhat stronger wind was observed at a height of $450 \mathrm{~cm}$ and a weaker wind inside the tree canopies (see Table 3). Temperatures were $3^{\circ}-4^{\circ}$ higher than during the spring assessments. Deviations in meteorological conditions in comparison with the spring test were not excessive but did exist. By comparing Tables 5 and 6 with Tables 7 and 8 , it becomes evident that the average drift values are significantly lower during the summer assessments in comparison with those determined during the spring applications. This is due to the increased canopy density and 
Table 7 Mean drift percentages $(\% \pm \mathrm{SD} ; n=20)$ at specific positions in relation to the type of sprayer, tree training system and sprayer travel speed when spraying with fine droplets (VMD 450-470 $\mu \mathrm{m}$ ) during summer assessment (August 16, BBCH 78-79)

\begin{tabular}{|c|c|c|c|c|c|c|}
\hline \multirow[t]{2}{*}{ Sampling position } & \multicolumn{2}{|c|}{ Type of sprayer } & \multicolumn{2}{|c|}{ Tree training system } & \multicolumn{2}{|l|}{ Driving speed } \\
\hline & Axial & Radial & SSP & MSP & $5 \mathrm{~km} \mathrm{~h}^{-1}$ & $10 \mathrm{~km} \mathrm{~h}^{-1}$ \\
\hline $\mathrm{BR}$ & $20.59 \pm 2.41$ & $13.45 \pm 1.03$ & $19.29 \pm 2.03$ & $14.76 \pm 2.33$ & $17.72 \pm 2.67$ & $16.82 \pm 3.21$ \\
\hline UT & $10.78 \pm 2.60$ & $10.20 \pm 2.05$ & $10.99 \pm 2.07$ & $9.99 \pm 1.45$ & $10.92 \pm 1.99$ & $10.06 \pm 2.13$ \\
\hline $1 \mathrm{~m}$ & $10.52 \pm 2.11$ & $9.79 \pm 1.99$ & $10.86 \pm 1.87$ & $9.45 \pm 1.00$ & $10.65 \pm 2.34$ & $9.65 \pm 1.87$ \\
\hline $2.5 \mathrm{~m}$ & $5.77 \pm 1.03$ & $4.10 \pm 0.71$ & $5.69 \pm 0.45$ & $4.18 \pm 0.33$ & $5.29 \pm 0.14$ & $4.58 \pm 0.11$ \\
\hline $5 \mathrm{~m}$ & $2.11 \pm 0.33$ & $1.19 \pm 0.12$ & $1.98 \pm 0.14$ & $1.31 \pm 0.12$ & $1.82 \pm 0.10$ & $1.48 \pm 0.06$ \\
\hline $10 \mathrm{~m}$ & $0.69 \pm 0.13$ & $0.36 \pm 0.16$ & $0.65 \pm 0.09$ & $0.40 \pm 0.10$ & $0.64 \pm 0.33$ & $0.41 \pm 0.27$ \\
\hline $25 \mathrm{~m}$ & $0.21 \pm 0.04$ & $0.07 \pm 0.01$ & $0.16 \pm 0.02$ & $0.12 \pm 0.01$ & $0.17 \pm 0.09$ & $0.11 \pm 0.05$ \\
\hline $50 \mathrm{~m}$ & $0.05 \pm 0.02$ & $0.02 \pm 0.01$ & $0.04 \pm 0.01$ & $0.03 \pm 0.01$ & $0.04 \pm 0.02$ & $0.03 \pm 0.01$ \\
\hline
\end{tabular}

$S S P$ super spindle trees, $M S P$ modified slender spindle trees, $B R$ between tree rows, $U T$ under trees

Table 8 Mean drift percentages $(\% \pm \mathrm{SD} ; n=20)$ at specific positions in relation to the type of sprayer, tree training system and sprayer travel speed when spraying with fine droplets (VMD 450-470 $\mu \mathrm{m}$ ) during summer assessment (August 16, BBCH 78-79)

\begin{tabular}{|c|c|c|c|c|c|c|}
\hline \multirow[t]{2}{*}{ Sampling position } & \multicolumn{2}{|l|}{ Type of sprayer } & \multicolumn{2}{|c|}{ Tree training system } & \multicolumn{2}{|l|}{ Driving speed } \\
\hline & Axial & Radial & SSP & MSP & $5 \mathrm{~km} \mathrm{~h}^{-1}$ & $10 \mathrm{~km} \mathrm{~h}^{-1}$ \\
\hline $\mathrm{BR}$ & $25.87 \pm 2.30$ & $17.06 \pm 1.44$ & $24.22 \pm 1.04$ & $18.71 \pm 1.01$ & $21.80 \pm 4.73$ & $21.13 \pm 5.06$ \\
\hline UT & $12.61 \pm 2.77$ & $11.22 \pm 1.99$ & $12.51 \pm 0.65$ & $11.32 \pm 0.13$ & $12.16 \pm 2.77$ & $11.67 \pm 3.11$ \\
\hline $1 \mathrm{~m}$ & $11.39 \pm 1.78$ & $10.31 \pm 1.56$ & $11.57 \pm 0.23$ & $10.14 \pm 0.12$ & $11.25 \pm 1.23$ & $10.45 \pm 0.99$ \\
\hline $2.5 \mathrm{~m}$ & $5.22 \pm 1.05$ & $2.08 \pm 0.41$ & $4.56 \pm 0.75$ & $2.73 \pm 0.32$ & $4.03 \pm 0.21$ & $3.26 \pm 0.07$ \\
\hline $5 \mathrm{~m}$ & $0.95 \pm 0.22$ & $0.54 \pm 0.17$ & $0.87 \pm 0.14$ & $0.62 \pm 0.17$ & $0.83 \pm 0.08$ & $0.66 \pm 0.04$ \\
\hline $10 \mathrm{~m}$ & $0.35 \pm 0.02$ & $0.19 \pm 0.02$ & $0.26 \pm 0.04$ & $0.28 \pm 0.06$ & $0.36 \pm 0.02$ & $0.24 \pm 0.03$ \\
\hline $25 \mathrm{~m}$ & $0.09 \pm 0.01$ & $0.04 \pm 0.01$ & $0.06 \pm 0.02$ & $0.07 \pm 0.03$ & $0.07 \pm 0.01$ & $0.06 \pm 0.02$ \\
\hline $50 \mathrm{~m}$ & $0.006 \pm 0.002$ & $0.006 \pm 0.003$ & $0.008 \pm 0.003$ & $0.007 \pm 0.003$ & $0.009 \pm 0.004$ & $0.008 \pm 0.004$ \\
\hline
\end{tabular}

SSP super spindle trees, MSP modified slender spindle trees, $B R$ between tree rows, $U T$ under trees

filtering capacity of the trees during the summer. Thus, drift was $70-80 \%$ lower during the summer in comparison with the drift measured in the spring. The relations among some studied factors (e.g. training system vs. sprayer travel speed and sprayer type vs. sprayer travel speed) were the same as in the spring tests, but not for all (e.g. training system vs. droplet size and sprayer speed vs. droplet size).

During fine spraying (VMD 150-170 $\mu \mathrm{m}$ ), the effects of sprayer type and training system were significant for most of the positions analysed (see Table 7; axial vs. radial and SSP vs. MSP). The differences between the two sprayer types and two training systems were significant at BR as well as at the $2.5-50 \mathrm{~m}$ positions (see Table 7). The travel speed had a significant effect on drift during fine spraying in some but not in most positions. Differences were significant at 2.5 and $5 \mathrm{~m}$ positions (5.28 vs. $4.58 \%$ and 1.82 vs. $1.48 \%$ ). As seen in Table 7, in summer, the differences in BR and UT deposits were not significant at 5 and $10 \mathrm{~km} \mathrm{~h}^{-1}$ speeds during fine spraying (17.72 vs. $16.82 \%$ and 10.92 vs. $10.06 \%$ ); this provides a contrast to the spring applications (Table 5; BR; 34.38 vs. $32.14 \%$ and UT; 34.15 vs. $32.14 \%$ ) when differences were significant. As a result of the speed increase from 5 to $10 \mathrm{~km} \mathrm{~h}^{-1}$, the following drift reductions (average axial + radial and SSP + MSP) were determined during fine spraying: $1 \mathrm{~m}$ (9.52\%), $2.5 \mathrm{~m}(13.5 \%), 5 \mathrm{~m}(18.8 \%), 10 \mathrm{~m}(35.4 \%)$, $25 \mathrm{~m}(34.8 \%)$ and $50 \mathrm{~m}(35.5 \%)$.

During coarse spraying, the relations among the given factors were slightly different to those determined during fine spraying (compare data from Tables 7, 8). Significant differences in the average amount of drift between axial-fan and radial-fan sprayers were detected at positions BR, 2.5, 10 and $25 \mathrm{~m}$ (see Table 8; axial vs. radial). When comparing deposits in SSP and MSP orchard, we can see that at most of positions, deposits were lower at MSP orchard. Those differences are again related to the greater filtering capacity of the MSP orchard and also to other undefined factors. It could be that internal orchard micro-weather conditions (atmospheric stability) and the higher resistance of the canopy to the air jet penetration altered the rate at 
which the sprayer's jet bent backwards and upwards when compared to the spring conditions. Thus, the droplet disintegration patterns and ratios among droplet size spectra in the spray cloud were changed. These kinds of effects were shown to play an important role when comparing results of drift assessment between different types of sprayers and types of tree training systems (Walklate 1992; Miller et al. 2000).

The sprayer travel speed had a significant influence on the drift values during coarse spray only at distances from 2.5 to $10 \mathrm{~m}$ from the edge of the orchard (see Table 8). As a result of the speed increase from 5 to $10 \mathrm{~km} \mathrm{~h}^{-1}$, the following average drift reductions (average axial + radial and SSP + MSP) were determined during coarse spraying: $1 \mathrm{~m}(7.14 \%), 2.5 \mathrm{~m} \mathrm{(19.1 \% ),} 5 \mathrm{~m} \mathrm{(20.7 \% ),} 10 \mathrm{~m}$ $(21.2 \%), 25 \mathrm{~m}(23.8 \%)$ and $50 \mathrm{~m}(11.1 \%)$. These data demonstrate that the increase in sprayer travel speed significantly affected drift even during the summer period with the coarse spraying applications. The increase in travel speed decreased ground deposits inside of orchard, which might be speculating, because it is not significant (see Fig. 3; right side). We can only assume that the increase in sprayer travel speed has a potential to mitigate endo-drift, which is one of the main weaknesses of coarse droplet spraying. The effect of speed increase on ground deposit reduction was lower in magnitude in coarse spraying than in fine spraying.

The effects of droplet size on ground deposits inside the orchard were similar to the ones determined during the spring period (compare left and right side of Fig. 3). The coarse spraying did not result in that much higher endodrift, as was the case during the spring period. This was probably due to the interactive effect of increased filtering capacity of the tree canopy and lower side wind speeds inside the orchard at 150 and $300 \mathrm{~cm}$ heights (see Table 3).

The interactive effect of sprayer speed and tree training system was similar during the spring test. The drift at outside positions was lower in MSP trees, and the reduction rate due to the speed increase was slightly lower in the MSP orchard than in the SSP orchard (compare left and right side of Fig. 4). The reduction rate due to the speed increase established during the summer period was lower than the one established during the spring period. The spring period is the most critical period for pesticide drift because the filtering capacity of trees is very low.

It is particularly common in spring that one is forced to spray many times because of longer periods of rainy weather and the short curative effectiveness of fungicides even when relatively strong winds are blowing (more than $1.5-2 \mathrm{~m} \mathrm{~s}^{-1}$ ). This study does suggest that an increase in sprayer travel speed can be considered one of the useful drift reduction measures, especially during spring spray applications, when tree canopy filtering capacity is low. On the other hand, one needs to be aware that the potential increase in sprayer travel speed is limited by the quality of spray deposition, which needs a certain level to ensure high biological efficiency of the pesticides, and by the topographic characteristics of the orchard terrain, which often limit the ergonomics of driving.

The results of this study indicate that an increase in sprayer speed from 5 to $10 \mathrm{~km} \mathrm{~h}^{-1}$ yields the following average reductions in spray drift percentages for specific downwind positions from the edge of an orchard planted with dwarf apple trees in the spring period: $1 \mathrm{~m}(6-11 \%)$, $2.5 \mathrm{~m}(8-14 \%), 5 \mathrm{~m}$ (9-19\%), $10 \mathrm{~m} \mathrm{(20-37 \% ),} 25 \mathrm{~m}$ $(60-70 \%)$ and $50 \mathrm{~m}(60-80 \%)$; and in the summer period: $1 \mathrm{~m}(5-9 \%), 2.5 \mathrm{~m}(8-12 \%), 5 \mathrm{~m}(10-15 \%), 10 \mathrm{~m}$ (20-25\%), $25 \mathrm{~m}(20-25 \%)$ and $50 \mathrm{~m}(10-13 \%)$.

\section{Conclusion}

All tested factors had a significant effect on spray drift during the spray application in the apple orchard with dwarf trees. The relative significance of factors is different when comparing results of the spring and summer applications and is comparable with orchards trained in the form of super spindle (SSP) or the modified slender spindle trees (MSP). The increase in sprayer travel speed can be considered as an applicable drift reduction measure. The rate of exo-drift reduction due to the sprayer speed increase (from 5 to $10 \mathrm{~km} \mathrm{~h}^{-1}$ ) is higher during the spring applications when compared to summer applications.

The exo-drift reduction expectations consequent to the increase in sprayer travel speed are higher with the axialfan than with the radial-fan sprayer and higher in the SSP than in the MSP orchard. Regarding drift reduction, radialfan sprayers with air spouts can be considered as more suitable for spraying in modern orchards with dwarf tress than standard axial-fan sprayers.

More detailed research on endo-drift is needed. The interaction between sprayer speed, droplet size and endodrift is different in fine spraying compared to coarse spraying. Coarse spraying, which is a standard drift reduction measure, can result in significant increase in endo-drift. Decreasing exo-drift at the cost of increasing endo-drift is not a good approach for drift management in orchards.

Acknowledgments This article was created as a result of the applied project "Establishing a national system of flexible pesticide buffer zones near water, protected and urban areas" (Grant No. V41134). The project was funded by the Public Research Agency of the Republic of Slovenia and the Ministry of Agriculture, Forestry and Food of the Republic of Slovenia. The authors also acknowledge the vital contributions made by the following colleagues: Matjaž Sagadin, who was responsible for the field measurements and Professor Michelle Gadpaille, for her editing of the manuscript. 


\section{References}

Anonymous (2005) ISO standard (ISO/FDIS 22866:2005): Equipment for crop protection-methods for field measurement of spray drift. Geneva

Arvidsson T (1997) Spray drift as influenced by meteorological and technical factors-a methodological study. Swedish University of Agricultural Sciences. Acta Univ Agric Suec Agrar 71:1-144

Bondesan D, Rizzi C, Giuliani G, Angeli G, Ioriatti C, Fondazione E (2012) Technical solutions to reduce drift of pesticides in apple orchards of Trentino. In: Proceedings of Fourth European Workshop on Standardised Procedure for the Inspection of Sprayers-SPISE 4 (Lana, South Tyrol), pp 224-227

Celen IH, Arin S, Durgut MR (2008) The effect of the air blast sprayer speed on the chemical distribution in vineyard. Pak $\mathbf{J}$ Biol Sci 11:1472-1476

Cross JV (1991) Patternation of sprayer mass flux from axial fan airblast sprayers in the orchard. Br Crop Prot Counc Monogr 46:15-22

Cross JV, Walklate PJ, Murray RA, Richardson GM (2001) Spray deposit and losses in different size apple trees from an axial fan orchard sprayer: 2. Effects of spray quality. Crop Prot 20:333-343

Cross JV, Walklate PJ, Murray RA, Richardson GM (2003) Spray deposit and losses in different size apple trees from an axial fan orchard sprayer: 3 . Effects of air volumetric flow rate. Crop Prot 22:381-394

Delele MA, Jaeken P, Debaer C, Baetens K, Endalew AM, Ramona H, Nicolaï BM, Verboven P (2007) CFD prototyping of an airassisted orchard sprayer aimed at drift reduction. Comput Electron Agric 55:16-27

Derksen RC, Gray RL (1995) Deposition and air speed patterns of aircarrier apple orchard sprayers. Trans ASAE 38(1):5-11

Derksen RC, Krause CR, Fox RD, Brazee RD, Zondag A (2006) Effect of application variables on spray deposition, coverage, and ground losses in nursery tree applications. J Environ Hortic 24(1):45-52

Derksen RC, Zhu H, Fox RD, Brazee RD, Krause CR (2007) Coverage and drift produced by air induction and conventional hydraulic nozzles used for orchard application. Trans ASABE 50(5):1493-1501

Endalew AM, Debaer C, Rutten N, Vercammen J, Delele MA, Ramon H, Nicolaï BM, Verboven P (2011) Modelling pesticide flow and deposition from air-assisted orchard spraying in orchards: a new integrated CFD approach. Agric For Meteorol 150:1383-1392

Endalew AM, Dekeyser D, Nuyttens D, Goossens T, Hendrickx N, Duga AT, Nicolaï BM, Verboven P (2012) Assessment of orchard sprayers using fluid dynamics. Asp Appl Biol 114:413-420

Fox RD, Reichard DL, Brazee RL (1985) A model study of the effect of wind on air sprayer jets. Trans ASAE 28:83-88

Fox RD, Reichard DL, Brazee RL, Hall FR (1990) Downwind residue from air spraying of a dwarf apple orchard. Trans ASAE 33:1104-1108

Ganzelmeier H, Rautmann D, Spangenberg R, Streloke M, Herrmann M, Wenzelburger HJ, Walter HF (1995) Studies on the spray drift of plant protection products. Blackwell WissenschaftsVerlag GmgH, Berlin

Garthwaite DG, Barker I, Parrish G, Smith L (2010) Pesticide usage survey report 225-orchards and fruit stores in Great Britain 2008. Agricultural Survey Team Food and Environment Research Agency, Sand Hutton York

Heijne B, Wenneker M, van de Zande JC (2002) Air inclusion nozzles don't reduce pollution of surface water during orchard spraying in the Netherlands. Asp Appl Biol 66:193-199
Hendrickx N, Goossens T, Endalew AM, Dekeyser D, Nuyttens D, Verboven P (2012) Assessment of orchard sprayers using field trials. Asp Appl Biol 114:405-412

Jejčič V, Godeša T, Hočevar M, Širok B, Malneršič A, Štancar A, Lešnik M, Stajnko D (2011) Design and testing of an ultrasound system for targeted spraying in orchards. J Mech Eng 57(7-8):587-598

Matthews GA (2000) Chapter 2 - Targets of pesticide deposition. In: Matthews GA (ed) Pesticide application methods, 3rd edn. Blackwell, London, pp 17-50

Meier U (1997) Growth stages of mono- and dicotyledonous plantsBBCH monograph. Blackwell, Berlin and Vienna

Miller DR, Stoughton TE, Steinke WE, Huddleston EW, Ross JB (2000) Atmospheric stability effects on pesticide drift from an irrigated orchard. Trans ASAE 43(5):1057-1066

Nuyttens D, de Schampheleire M, Steurbaut W, Baetens K, Verboven P, Nicolaï BM, Ramon H, Sonck B (2006) Experimental study of factors influencing the risk of drift from field sprayers, Part 2: spray application technique. Asp Appl Biol 77(2):331-339

Ross LJ, Bennett KP, Kim KD, Hefner K, Hernandez J (1997) Reducing dormant spray runoff from orchards. Project research report EH-9703, Environmental protection agency of California, Sacramento California, pp 15-23

Sehsah EME (2007) Study of effects of forward speed and nozzles types on the spray characteristics of air assistance hydraulic sprayer. Misr J Agric Eng 24(1):75-87

Świechowski W, Durochowski G, Holownicki R, Godyń A (2004) Penetration of air within the apple tree canopy as affected by the air jet characteristics and travel velocity of the sprayer. Electron J Pol Agric Univ 7(2):1-8

Triloff $\mathrm{P}$ (2005) An extended tree roe volume dosing model: adjusting pesticide dose rate, water volume and air volume rate by forward speed. Ann Rev Agric Eng 4(1):69-80

Triloff P (2011) Verlustreduzierter Pflanzenschutz im Baumobstbau-Abdriftminimierung und Effizienzsteigerung durch baumformabhängige Dosierung und Luftführung. Verlag Ulrich E, Grauer

Urek G (2012) The use of pesticides and identification of possible solutions for their rational use in Slovenia. Monograph series of Agricultural Institute of Slovenia 2012, Ljubljana, Slovenia, pp 103-162

van de Zande JC, Stallinga H, Michielsen JMP, van Velde P (2005) Effect of sprayer speed on spray drift. Ann Rev Agric Eng 4(1):129-142

Walklate PJ (1992) A simulation study of pesticide drift from an airassisted orchard sprayer. J Agric Eng Res 51:263-283

Walklate PJ, Richardson GM, Cross JV (1996) Measurements of the effect of air volumetric flow rate and sprayer speed on drift and leaf deposit distribution from an air-assisted sprayer in an apple orchard. In: Proceedings of Agricultural Engineering Research, Spain, Madrid, Paper 96A:131-140

Wenneker M and van de Zande JC (2008) Drift reduction in orchard spraying using a cross flow sprayer equipped with reflection shields (Wanner) and air injection nozzles. CIGR Ejournal, $\mathrm{X}: 1-10$. http://www.cigrjournal.org/index.php/Ejounral/article/ viewFile/1257/1114. Accessed 20 June 2013

Whitney J, Salyani M (1991) Deposition characteristics of two aircarrier sprayers in citrus trees. Trans ASAE 34(1):47-50

Yarpuz-Bozdogan N, Bozdogan AM (2009) Comparison of field and model percentage drift using different types of hydraulic nozzles in pesticide applications. Int J Environ Sci Technol 6(2):191-196 